Article

\title{
It Does Matter How You Get to the Top: Differentiating Status from Reputation
}

Karen D. W. Patterson ${ }^{1}{ }^{*}$, David Eduardo Cavazos ${ }^{1}$ and Marvin Washington ${ }^{2}$

1 Anderson Schools of Management, The University of New Mexico, MSC05-3090 Albuquerque, Albuquerque, NM 87131, USA; E-Mail: dcavazos@unm.edu

2 Strategic Management \& Organization, 4-30F Faculty of Business Building, University of Alberta, Edmonton, AB T6G 2R6, Canada; E-Mail: washingt@ualberta.ca

* Author to whom correspondence should be addressed; E-Mail: Patterson@ unm.edu; Tel.: +1-505-277-2807; Fax: +1-505-277-7108.

Received: 30 September 2013; in revised form: 19 February 2014 / Accepted: 28 February 2014 / Published: 4 April 2014

\begin{abstract}
Status and reputation have long been recognized as important influences in management research and recently much attention has been paid to defining the two concepts and understanding how they are utilized by organizations. However, few strategic management studies have identified the different methods through which status and reputation are constructed. While reputation has been linked with a history of quality, and status has been identified as an externally assigned measure of social position, empirical studies have been highly idiosyncratic in their identification of the mechanisms used to obtain either construct. This paper attempts to rectify that gap in the literature by identifying two distinct methods used to obtain reputation and status. We argue that certification contests can be used to increase organizational reputation and tournament rituals can be used to increase organizational status. We build theoretical propositions regarding the use of certification contexts and tournament rituals to show how reputation and status are achieved through similar, but distinct, methods and further the research on teasing apart these two important and intertwined concepts.
\end{abstract}

Keywords: status; reputation; certification contests; tournament rituals 


\section{Introduction}

The role of intangible resources in achieving competitive advantage has been a subject of great importance to both scholars and practitioners. Factors such as leadership, creativity, status and reputation can be key to achieving competitive advantage [1]. In particular, there has been a renewed interest in understanding the impact of status and reputation on organizational outcomes. Status has been defined in a number of ways across different literatures but "is broadly understood as the position in a social hierarchy that results from accumulated acts of deference [2-4]" and is externally attributed [5]. While highly intertwined with status, reputation has been defined as a measure of past quality, performance or actions [5-7]. While both status and reputation have been utilized extensively in sociology research, distinguishing the methods by which the two are constructed remains an important question [5,8], particularly for strategic management researchers.

Significant efforts have gone into teasing apart status effects from reputation effects [5-7,9]. In a study of venture capital (VC) investment decisions, Dimov, Shepherd, and Sutcliffe [9] found that high status VC firms with a higher financial reputation avoided early stage investments more than lower status VC firms with a high financial reputation. Likewise, Ertug and Castellucci [6] found that reputation and status have different effects on quality, revenues and resource acquisition strategies. However, there remain specific challenges in conceptualizing and differentiating between the two constructs and their sources. Dimov et al. [10] described the differences between status and reputation as follows: "a firm's reputation is established based on its past performance, whereas status is the consequence of its pattern of social relationships and the quality of its network partners". However, other research has used their reputation definition as a measure of status [8]. Thus, Washington and Zajac [5], note that "it is typically difficult to identify differences in competitive organizational outcomes that can be confidently attributed to socially based differences in status, rather than quality or merit-based differences that correspond to reputation". One of the reasons why strategic management scholars have viewed reputation and status similarly is because of their reliance on stakeholder evaluations and institutional norms [11-13]. This is similar to the confusion between reputation and legitimacy $[14,15]$.

We seek to advance the literature examining the differential contributors to status and reputation with regard to organizational performance. Distinguishing between status and reputation can help strategic management scholars explore the two in more detail and help managers identify key drivers of the two processes within their organizations. We propose that industries have distinct social processes that can build or reinforce organizational status and reputation. Such processes include certification contests, processes that assess an organization's performance [16], and tournament rituals, processes that determine an organization's social standing [17]. Certification contests are social mechanisms that allow for comparison among organizations [18]. These mechanisms rely on a distinction between winners and losers that is determined by the attainment of particular performance criteria. Tournament rituals, on the other hand, are social mechanisms that help to organize categories of actors into common social standings [17] and signal commonalities among participants.

We theorize that distinct social processes can develop or reinforce status and reputation by outlining how success in certification contests leads to an organization's reputation while success in tournament rituals produces organizational status. Because the two processes are rooted in differing conceptions of 
organizational value, they will generally result in distinct social orderings of organizations. Successful certification contests will tend to build or reinforce organizational reputation; while tournament rituals will tend to build or reinforce organizational status. We also argue that status and reputation will have unique effects on the perception of organizational activities. Specifically, status will tend to moderate the effects of organization activities with regard to social stratification. Reputation will moderate the effects of organization activities with regard to perception of quality.

We first distinguish between organizational status and reputation by reviewing the relevant literature in both areas. We then examine literature dealing with the conception of The Matthew Effect and how such work can inform organizational research dealing with status and reputation. Propositions are developed by integrating research in status and reputation with the literature dealing with certification contests and tournament rituals. We conclude this research with a discussion on directions for future research.

\section{Status}

As mentioned previously, status is an externally attributed position in a social hierarchy that results from accumulated acts of deference [4]. The rewards of status have been researched exhaustively (for a review of this research, see [19]). Research has long suggested that high status organizations are able to gain a competitive advantage in the market [20,21]. Simmel [22] viewed status as the difference between an organization and the perceptions regarding organizational overall quality held by external market actors. This was an important construct in Simmel's work because he argued that rewards were not determined by an organization's performance, but based on social position. Weber included status ("staendische lage") as one of the dimensions that can be used to describe social ranking systems [23]. "The concept of status invokes the imagery of a hierarchy of positions - a pecking order - in which an individual's location within that hierarchy shapes others' expectations and actions toward the individual and thereby determines the opportunities and constraints that the individual confronts [24]." From this perspective, status provides a somewhat stable ordering system that allows for prescribed associations between actors or organizations of similar position within the system.

Status, however, is not a purely societal-level phenomenon and inconsistent views on stratification systems extend beyond the societal level and are significantly more complex than linear projections of individual or organizational status [19,25]. An often under-emphasized part of Stinchcombe's classic [26] paper is his treatise on organizational stratification. Stinchcombe calls for a general theory of status that is specific to organizations. He suggests that when attempting to describe individual status hierarchies the family or individual may be an appropriate level of analysis [26] but, when studying organizational stratification systems, different levels of analyses should be used. "What is needed then, is a general measure of the predominant method of organizing social life into units which are evaluated relative to each other, and which reap the benefits of high rank or the disadvantages of low rank [26]." Or, said differently, "in markets, as in athletic competitions or social groups, "what is possible' is in large measure socially defined by qualitatively differentiated peers looking to each other for cues regarding appropriate aspirations and performance [24]." These sentiments have been supported in subsequent research that has found that individual and organizational networks influence status hierarchies, both reinforcing status and constraining it $[4,19,27,28]$. 


\subsection{Status as a Resource}

Previous research, building upon Simmel's conception of status, describes status as an indicator of quality [8] and as a cumulative measure of an organization's performance [29]. This literature places more emphasis on status as a resource or capital that can be gained and lost. In his study of investment banks [8,30], Podolny suggests that the social stratification system of investment banks can be explained by looking at status dynamics between the banks. Status, in Podolny's work, is determined by looking at the position of investment banks on tombstone announcements. Companies use tombstone announcements, typically found in the Wall Street Journal, to advertise initial stock offerings. The banks that underwrite the offering are listed on the tombstone in order of status. Podolny found that the investment banks that were high status (listed near the top of the tombstone) were able to underwrite the offerings for less than those on the bottom.

Another example of the work on organizational status is present in Rao's [16] study of automobile manufacturers. His study found that in the early days of the automobile industry winning automobile durability and speed contests improved a manufacturer's chance of survival, even though these contests represented extreme uses of the automobile. All of the above studies treat status-winning automobile contests, affiliating with high status organizations, and minimizing associations with low status organizations - as a resource that, if accumulated, can help an organization obtain its desired outcomes. This is different from Weber's original interpretation of status as social standing in that status is less a function of performance (albeit under unrealistic conditions) or quality (based on ritual contests) but rather a complex function of factors, many unrelated to performance or quality, often based on relationships.

\subsection{Status as Social Standing}

One area where most researchers agree regarding status is that it does, to some extent, result from differences in social rank, the consequences of which include privilege or discrimination $[5,15,23]$. Weber suggests that status is founded on "style of life", "formal education", "hereditary or occupational prestige", or "consumption pattern of goods". Such social rankings create hierarchies among competitors that influence consumer perception and preferences [8]. Status additionally influences organizational affiliations and network ties, which subsequently enhance or limit firm market share [28,31], capacity for innovation [32], and Ricardian rents [8]. Podolny [8] developed a construct of status that was largely dependent on consumer perception; while Washington and Zajac [5] show that status is conferred upon an actor by others. They further find that high status organizations receive benefits above and beyond what they would receive based upon their performance or quality.

Status is generally regarded as shared social perceptions viewing people who belong to one social group as more esteemed and competent than those who belong to another social group [33]. Hence, status may stem from an organization's historical legacy in the form of positive or negative associations that may have little to do with assessments of quality [5]. Rather, status depends upon the relative position of an individual, group or organization as compared with similar others [15]. Furthermore, research in the sociology of art literature has shown that, once obtained, high status is difficult to lose, especially through simple association with lower-status others [25,34]. In fact, status can be transferred from 
high-status actors to lower-status actors or organizations through associations or endorsements without resulting erosion in status [25].

Status is a relational component of social structure that is based on perceptions of various organizational outcomes applied to a given firm by external actors [5]. Furthermore, as illustrated by Podolny [8] as well as Benjamin and Podolny [35], perception is formed after market transactions. Status is a cognitive construction that is negotiated among various audiences [15]. Therefore, an organization's status may be conceptualized as an intangible resource, in that it contributes to performance differences, it is rare, complex and difficult to trade or imitate $[1,36]$.

\section{Reputation}

A concept similar to status, with origins in the economic game theory literature, is reputation. Fombrun and his colleagues [12,29,37] argue that an organization's reputation is a valuable, intangible asset that should be managed. Reputation is important because it "informs us about what products to buy(and) it calls attention to a company's attractive features and widens the options available to its managers, for example, whether to charge higher or lower prices for products and services, or to implement innovative programs" [29]. Fombrun suggests that a corporate reputation "is a collective representation of a firm's past actions and results that describes the firm's ability to deliver valued outcomes to multiple constituents" [38]. Likewise, Jensen and Roy [7] empirically show that decision makers use reputation as a more specific measure of firm quality than status. They argue that reputation is a direct representation of past quality and show that decision makers use it as a proxy for future firm behavior.

A major characteristic of reputation, distinguishing it from status, is that it is a collective assessment of a company's attractiveness to a specific group of stakeholders relative to a reference group with which the company competes for resources [38]. Thus, like status, reputation involves external assessment and is a relative construct. Unlike status, however, reputation involves an assessment of attractiveness along a specific performance dimension. As a result, reputation may vary across audiences and attributes. Reputation is, thus, attribute specific in that it is attributed to specific firm behaviors [7].

Because actors do not have perfect information and do not survey the population of services or products of interest, actors rely on a firm's reputation for a particular attribute when determining which product or service to purchase. Thus, acquiring a good reputation for a particular activity can lead to a potential competitive advantage [20,21]. Unlike status, which is difficult to lose and can be achieved at various stages in a career or organizational life-cycle [21,39], reputation can be eroded over time but also takes time to attain $[40,41]$.

In terms of the origins of reputation, it can be seen as "the consumer's subjective evaluation of the perceived quality of the product [42], or "stakeholder's perceptions about an organization's ability to create value relative to competitors [43]." Studies on reputation have shown such assessments to be derived from views of firm activities and results, economic performance, social responsibility, media visibility and size [12]. CEO performance builds a firm's reputation [18] and, similarly, measures of organizational financial performance can enhance a firm's reputation [44]. 


\section{Underlying Processes of Status and Reputation}

Perhaps a major reason for the confusion regarding the use of status and reputation is the equal weight of their reliance on shared understandings of industry norms. Status, for instance, in its basis in social rank, suggests that it is conferred upon organizations based on the extent to which they conform to particular desirable attributes [5]. Reputation, in its reliance on signals regarding what particular performance characteristics are favorable to specific stakeholders [12], relies on such norms as well.

Another point of confusion between status and reputation is that both are often reflected through rankings. Rankings provide quantifiable information to the public about relative positional status $[45,46]$. Doing well in rankings is crucial as high rankings lead to higher prices for products [29], better access to capital $[16,47]$ and reduced risk of organizational mortality. Also, organizations with a high ranking feel good about themselves [45] and can provide clear direction for strategic action. "Rankings are a powerful tool that stakeholders can use to influence organizational actions [46]."

Hence, while status and reputation are related, the subtle difference between status and reputation is the aspect of status that recognizes differences in social standing [5]. Reputation, meanwhile, reveals differences in specific performance dimensions that generate performance-based rewards. Their similarity comes from the fact that they both, to a degree, rely on norms and are socially constructed [15]. Their difference, however, lies in the fact that reputation is derived from performance along specific attributes, while status is a hierarchical measure of social standing.

\section{Certification Contests and Tournament Rituals}

There are varying bases for comparing firms in organizational research. Contests and tournaments, for instance, are considered social tests of products and organizations [48]; victories in such activities legitimate a given organization and improve reputation [16] or increase individual esteem among peers [49]. Certification contests allow organizations to provide evidence of better performance than their competitors. They also motivate organizations to devote resources to illustrate how they are meeting certain technical criteria deemed important within an industry and based on impartial and rational testing [16]. Victories in certification contests provide validity for organizations in the eyes of consumers by providing an understandable, measurable standard of performance and quality along a specific performance dimension [16]. Victories in contests have additionally been shown to improve firm financial performance [18]. Such victories will then lead organizations to publish and advertise victories in order to exploit the positive outcome of a comparison to rivals. Results of certification contests can determine access to resources [50], improve chances of survival [16], increase executive compensation [18] and provide opportunities for beneficial affiliations [8].

Certification contests, when based on evaluating organizational output, essentially provide a measure of specific organizational processes. These measures serve as market signals for consumers who seek information concerning organizational quality and performance. For instance, Consumer Reports reviews automobiles for particular attributes such as safety and reliability and rates them as "recommended" if the vehicle meets particular criteria for those attributes. Meeting such criteria requires automakers to perform particular activities or modify certain routines in their production and design process. Hence, because contests reveal relative performance along specific measurable 
attributes whose measures are available to specific firm stakeholders, we propose that victories in certification contests will enhance firm reputation along the dimensions compared in such contests.

Proposition One: Victories in certification contests will enhance firm reputation in the attributes needed to obtain victories in such contests.

The notion of tournament rituals relies on ritual theory [51,52] to describe rituals as processes that distribute organizational prestige and provide order to inter-organizational fields [17]. Rituals are said to serve as mechanisms for social integration that facilitate the transfer and expression of shared meanings [53]. Rituals additionally serve to organize individuals into coherent groups [54]. Empirical research in this area has examined ritualized practices, such as elections, to show that rituals allow participants to confirm their role within a social system [55].

Given that rituals reinforce shared meanings, tournament rituals serve to reinforce the legitimacy of participants [17]. Examples of such tournaments include the Oscars, Grammy Awards, and Tony Awards. Participation in these events is reserved only for those social actors deemed to be influential [56]. Tournament rituals, thus, serve as mechanisms to distribute status among those actors that are judged as worthy of participation [17]. Organizations that participate in rituals do so in order to reinforce social order, communicate values and provide meaning, among other activities [57]. Bothner, Podolny and Smith [49] further the social meaning behind tournament rituals (referred to as status tournaments by the authors) by emphasizing the elements of peer recognition and esteem-based components of such processes. Their findings show that past influence and status are more predominate in narrow, celebrity-centered status tournaments.

Our conception of tournament rituals is based on the work of Anand and Watson [17] who developed an integrated conception of tournament rituals grounded in ritual theory. Ritual theory, as pointed out by Anand and Watson [17], is composed of three views concerning the function and impact of ritual on society. The solidarity view sees ritual as a means to reinforce accepted views [52]. The agonistic view [53] explains rituals as a means for dominant groups to assert control. The sense-making view sees ritual as a way to make sense of action [58]. Tournament rituals, composed of symbolic routines, provide an opportunity for actors to come together for a specific occasion. From any perspective the 'winner' of a tournament ritual is not presumed to provide higher quality than his or her peers, but instead is bestowed with a significant and differentiable level of perceived social value.

Unlike certification contests, tournament rituals are not necessarily associated with a sense of technical and measurable past quality or performance. While certification contests are a measure of organizational performance along particular dimensions, rituals serve to make sense of social conditions by establishing ceremonial judgments of worth [59]. Such judgments perpetuate accepted practices [51] by reinforcing desirable qualities and values. Furthermore, rituals serve as general judgments of the worthiness of actors and activities [57,59]. Participating in tournament rituals, an honor that is conferred upon participants, serves as an indicator of participant privilege and social standing [56]. The importance of the occasion is enhanced with a ceremonial structure that is designed to differentiate the process from routine field-level activities [17].

Rather than direct measures of organizational performance, rituals legitimate practices by recognizing those organizations whose practice is seen as most legitimate. Hence, tournament rituals, as Anand and Watson [17] found in a study of the Grammy Awards, develop inter-organizational 
fields by distributing prestige to those recognized as winners. As a result, winners of rituals will develop status rather than reputation.

Proposition Two: Actors recognized as winners in tournament rituals will develop higher status than those actors that are not recognized as winners.

While any actors may be allowed to enter a contest, provided they meet functional requirements, tournament ritual participants are often invited or nominated [57]. Higher status actors are more likely to participate in tournament rituals than lower status actors [2]. Organizational affiliations with higher status actors also increase the likelihood of participation in tournament rituals. This was illustrated empirically by Washington and Zajac [5] using the National Collegiate Athletic Association (NCAA) basketball tournament. Results of Washington and Zajac's empirical analysis suggest that tournament appearances are largely dependent on past appearances and desirable affiliations. The above results suggest that higher status organizations have a higher likelihood of earning invitations to such tournaments. Hence, a "Mathew Effect" as described by Merton [60] exists for tournament rituals. The Mathew Effect states that those with greater recognition will tend to get even more recognition than those in the same situation with less recognition. In the case of status, those with higher status are more likely to obtain invitations to status building rituals.

Proposition Three: Higher status actors are more likely to earn invitations to tournament rituals.

The Mathew Effect, inherent in tournament rituals, may be a primary reason why organizations with high status tend to maintain their status, up to a point [61]. In arenas such as MBA rankings, Academy Award winners, or even college football team bowl invitations, the elite (top 20 MBA programs, best actors, and top 20 football teams) tend to be comprised of the same organizations or people year after year. Although there are competitive dynamics that should change the rankings, the status structure allows those at the height of the prestige pyramid to stay there. As organizations that are high status receive more attention and visibility, their actions are universally perceived as high status, thus reinforcing the status ordering and adding to the stability of the system. Therefore, professors and students (in the MBA arena), directors and other actors (in the movie arena), and players and coaches (in the football arena) want to connect with high status organizations because either they consider them as good (high status) or they might be "basking in their reflected glory [62]." This leads to high status organizations maintaining their standing.

We additionally argue that the contests and rituals will have distinct dynamics in terms of who earns victories and who participates in the two types of activities. Victories in contests may not be predicted by previous victories nor are they indicative of future ones. Conversely, victories in tournament rituals have much stronger relationships to past and future victories. Contests, for instance, are based on organizational performance criteria, which theoretically are judged independently of previous performance. If such criteria are not met the organization will not earn a victory, regardless of past victories. Wade, Porac, Pollock and Graffin [18], for example, illustrate that CEO victories in certification contests are not associated with future firm performance. Furthermore, cumulative victories increase reputation at a decreasing rate [16]. This implies that organizations earning victories in one time period may not perform well in the following time period since potential gains from an additional victory will not be enough to offset the costs of allocating resources to win the contest. As 
opposed to status hierarchies (academy awards, MBA rankings, college football rankings), reputation hierarchies are filled with "one hit wonders". In terms of movie and record sales, there are many individuals or actors who sold numerous records and movies at one time, developed a great reputation, but could not parlay that into another "hit".

Because contests measure firm performance at a specific point in time along specified dimensions [16], firm victories in contests may not be predicted by past victories. A firm victory in and of itself does not necessarily enhance the likelihood of additional victories. Thus, specific firm capabilities that result in competitive advantage [1] may increase the likelihood of future firm victories; however, the distinction of having achieved past victories does not. As a result, researchers have characterized contest victories as "(S)mall chance events" and as "fortuitous events" [16]. Scholars have additionally noted that in some instances winners of contests in one particular time period may have lesser capabilities than winners in other time periods [63]. Therefore, because victories in certification contests are partially attributable to reputation, and victories in tournament rituals are partially attributable to status, the likelihood of repeated victories in the different types of contests will vary.

Proposition Four: The likelihood that an organization will earn repeated victories in certification contests is less than the likelihood that an organization will earn repeated victories in tournament rituals.

If certification contests are viewed as sources of pressure, varying performance may be explained as an instance of decoupling. In order to increase legitimacy and subsequent chances of survival, organizations will incorporate policies and procedures outlined by dominant rationalized concepts [59]. Conformity to such requirements, however, might conflict with organizational efficiency criteria and may be decoupled from organizational practice [59]. If contests are assumed to represent social tests of organizations [16], then losses in such contests would suggest that particular changes in firm behavior and/or strategy would be needed to earn a victory. However, organizations may not always respond to losses incurred in a certification contest. Oliver [64], for example, explains that organizations may avoid compliance to institutional pressure when actions are not subject to public approval. Furthermore, the lower the degree of financial/economic gain that is attainable from conformity the more likely avoidance will occur [64].

In terms of rituals, we argue that previous participation will increase the likelihood of future participation. Rituals have been shown to shape inter-organizational field evolution by recognizing whose practices are seen as worthy [17]. Influential actors have a higher likelihood of participating in the ritual and will, as a result, be favored over less influential actors [2,5,57]. Hence, participating in rituals may have as much influence on actor status as earning victories in rituals.

Proposition Five: The likelihood that an organization will participate in tournament rituals is dependent on past participation.

In sum, contests and rituals involve distinct processes. Certification contests involve direct measures of organizational performance along specific criteria. As a result, outcomes of contests allow comparisons of organizational quality. Such comparisons provide reliable measures of organizational reputation. Tournament rituals involve field level assessments of organizational worth and appropriateness. Actor participation in such tournaments is dependent on past appearances, and as a 
result, participation in these tournaments relies on past appearances and victories. Therefore, tournament ritual participation and results provide a reliable indicator of organizational status.

While reputation and status are no doubt correlated due to common foundations, the two diverge in how they are formed and reiterated throughout society. Reputation is largely based on utilitarian conceptions. While influenced by multiple factors that include social and organizational history, organizational culture and network centrality, an organization's reputation can be altered or eroded by the perceived changes in performance, as evidenced by certification contests. Status, on the other hand, is bestowed and constrained by similar established social norms, networks and perceptions of legitimacy, belonging or desirableness. Again, while the two may influence each other and share a common foundation, the paths to being are very different.

\section{Discussion}

This research draws important distinctions concerning the nature and origin of status and reputation that is of importance to both scholars and practitioners. For example, the automobile industry has tournament rituals such as the "Motor Trend Car of the Year" and certification contests such as NHTSA (National Highway Traffic and Safety Administration) crash tests and Consumer Reports reliability tests. Municipalities have similar processes such as published restaurant reviews and health inspection results that can impact the reputations of small businesses. Examining such processes empirically, within the framework proposed in this paper, would make important progress in distinguishing between the sources of reputation and status and how firms can implement initiatives to develop them.

The primary contribution this research makes is the provision of a process-based approach to the theoretical underpinnings, and empirical measurement, of status and reputation. Rather than attempting to define status and reputation based upon their outcomes alone, which continue to be convoluted, we provide for a process-based view of how the two constructs are actually created. By examining the origins of status and reputation, we are better able to recognize the different purposes of these constructs, one leading to perceptions of quality, the other reinforcing conceptions of legitimacy and desirability. The origins and processes of creating reputation and status, although related, clearly demarcated the differences in the two constructs.

Distinguishing between certification contests-contests that involve direct measures of organizational quality and/or performance — and tournament rituals — contests that involve perceptions of organizational legitimacy-allows the distinct effects of these different types of processes to be examined. We propose that the two are distinct processes that yield distinct outcomes. More specifically, victories in certification contests result in enhanced organizational reputation, while victories in tournament rituals result in organizational status. The purpose of contests is to test and compare performance among actors that share similar traits or qualities (classes of cars, types of acting or singing, etc.) while the purpose of tournament ceremonies is to bestow value and reiterate worth. Therefore, once again, although status and reputation are related, specifically in relation to their foundations, the outcomes of, and processes that lead to, status and reputation are not.

While status and reputation are distinct processes, the two are related in their dependence on perceptions about what is appropriate organizational behavior. This similarity, however, does not 
preclude their fundamental differences as to what kinds of organizational qualities they measure and where they come from. Instead, we propose the explanation of the constructs from their respective bases in conjunction with the process by which they can be created. Thus, our approach is capable of illustrating the similarities of status and reputation while also highlighting the differences that make each of the constructs valuable regardless of the other.

\section{Conclusion}

Our approach to distinguishing the sources of status from the sources of reputation offers theoretical and methodological clarity to a subject that has experienced more than the usual amount of discussion amongst researchers. Theoretically, it allows future scholars to be able to tease apart status from reputation in their constructs by examining differences between the contributing causes of the two concepts. Methodologically, it provides a basis for selecting and classifying one mechanism over another in terms of developing a research design. In addition, both certification contests and tournament rituals can be examined at multiple levels which allows for examination of reputation and status from a variety of perspectives. By taking a different perspective, namely examining the antecedents of status and reputation, strategic management researchers can more clearly define the specific actions and activities that lead to a good reputation or becoming a prestigious organization. Instead of only examining the outcomes of status and reputation which can be strongly intertwined, the examination of the mechanisms that lead to the two allow for a more intricate analysis of what actually makes up these highly debated and elusive concepts.

\section{Conflicts of Interest}

The authors declare no conflict of interest.

\section{Author Contributions}

All authors contributed equally to the development of the manuscript.

\section{References}

1. Barney, J.B. Firm resources and sustained competitive advantage. J. Manag. 1991, 17, 99-120.

2. Goode, W.J. A Celebration of Heroes; University of California Press: Berkeley, CA, USA, 1978.

3. Whyte, W.F. Social organization in the slums. Am. Sociol. Rev. 1943, 8, 34-39.

4. Sauder, M.; Lynn, F.; Podolny, J.M. Status: Insights from organizational sociology. Annu. Rev. Sociol. 2012, 38, 267-283.

5. Washington, M.; Zajac, E. Status evolution and competition: Theory and evidence. Acad. Manag. J. 2005, 2, 282-296.

6. Ertug, G.; Castellucii, F. Getting what you need: How reputation and status affect team performance, hiring, and salaries in the NBA. Acad. Manag. J. 2013, 56, 407-431.

7. Jensen, M.; Roy, A. Staging exchange partner choices: When do status and reputation matter? Acad. Manag. J. 2008, 51, 495-516.

8. Podolny, J.M. A status-based model of market competition. Am. J. Sociol. 1993, 98, 829-872. 
9. Dimov, D.; Shepard, D.A.; Sutcliffe, K.M. Requisite expertise, firm reputation, and status in venture capital investment allocation decisions. J. Bus. Ventur. 2007, 22, 481-502.

10. Dimov, D.; De Clercq, D. Venture capital investment strategy and portfolio failure rate: A longitudinal study. Entrep. Theory Pract. 2006, 30, 207-223.

11. Ashforth, B.; Gibbs, B. The double-edge of organizational legitimation. Organ. Sci. 1990, 1, 177-194.

12. Fombrun, C.; Shanley, M. What's in a name? Reputation building and corporate strategy. Acad. Manag. J. 1990, 33, 233-258.

13. Gioia, D.A.; Corley, K.G. Being good vs. looking good: Business school ranking and the circean transformation from substance to image. Acad. Manag. Learn. Educ. 2002, 1, 107-120.

14. Deephouse, D.; Carter, S.M. An examination of differences between organizational legitimacy and organizational reputation. J. Manag. Stud. 2005, 42, 329-360.

15. Bitektine, A. Toward a theory of social judgments of organizations: The case of legitimacy, reputation, and status. Acad. Manag. Rev. 2011, 36, 151-179.

16. Rao, H. The social construction of reputation: Contests, credentialing and legitimation in the American automobile industry: 1895-1912. Strateg. Manag. J. 1994, 15, $29-44$.

17. Anand, N.; Watson, M.R. Tournament rituals in the evolution of fields: The case of the Grammy Awards. Acad. Manag. J. 2004, 47, 59-79.

18. Wade, J.B.; Porac, J.F.; Pollock, T.G.; Graffin, S.D. The burden of celebrity: The impact of CEO certification contests on CEO pay and performance. Acad. Manag. J. 2006, 49, 643-660.

19. Piazza, A.; Castellucii, F. Status in organization and management theory. J. Manag. 2014, 40, 287-315.

20. Caves, R.E.; Porter, M.E. From entry barriers to mobility barriers: Conjectural decisions and contived deterrence to new competition. Q. J. Econ. 1977, 91, 241-261.

21. Weigelt, K.; Camerer, C. Reputation and corporate strategy: A review of recent theory and applications. Strateg. Manag. J. 1988, 9, 443-454.

22. Simmel, G. The Sociology of Georg Simmel; Wolfe, K.H., Transl; Free Press: New York, NY, USA, 1950.

23. Weber, M. Economy and Society: An Outline of Interpretive Sociology; Roth, G., Wittich, C., Eds.; University of California Press: Berkeley, CA, USA, 1978.

24. Podolny, J.M. Status Signals: A sociological Study of Market Competition; Princeton University Press: Princeton, NJ, USA, 2005.

25. Dubois, S.; Francois, P. Career paths and hierarchies in the pure pole of the literary field: The case of contemporary poetry. Poetics 2013, 41, 501-523.

26. Stinchcombe, A.L. Social structure and organizations. In The Handbook of Organizations; March, J.G., Ed.; Rand McNally: Chicago, IL, USA, 1965; pp. 142-193.

27. Lynn, F.; Podolny, J.M.; Tao, L. A sociological (de)construction of the relationship between status and quality. Am. J. Sociol. 2009, 115, 755-804.

28. Giuffre, K. Sandpiles of opportunity: Success in the art world. Soc. Forces 1999, 77, 815-832.

29. Fombrun, C.J. Reputation: Realizing Value from the Corporate Image; Harvard Business School Press: Boston, MA, USA, 1996. 
30. Podolny, J.; Phillips, D. The dynamics of organizational status. Ind. Corp. Chang. 1996, 5, 453-471.

31. Podolny, J.M.; Stuart, T.E.; Hannan, M.T. Networks, knowledge, and niches: Competition in the worldwide semiconductor industry: 1984-1991. Am. J. Sociol. 1996, 102, 659-689.

32. Podolny, J.M.; Stuart, T.A. Role-based ecology of technological change. Am. J. Sociol. 1995, 100, 1224-1260.

33. Webster, M.; Foschi, M. Status Generalization: New Theory and Research; Stanford University Press: Stanford, CA, USA, 1988; pp. 1-536.

34. Ginsburgh, V.; Weyers, S. Persistence and fashion in art. Italian Renaissance from Vasari to Berenson and beyond. Poetics 2006, 34, 24-44.

35. Benjamin, B.A.; Podolny, J.M. Status, quality and social order in the California wine industry. Adm. Sci. Q. 1999, 44, 563-589.

36. Peteraf, M. The cornerstone of competitive advantage: A resource based view. Strateg. Manag. J. 1993, 14, 179-191.

37. Rindova, V.; Fombrun, C.J. Constructing competitive advantage: The role of firm-constituent interactions. Strateg. Manag. J. 1999, 20, 691-710.

38. Fombrun, C. The building blocks of corporate reputation: Definitions, antecedents, consequences. In The Oxford Handbook of Corporate Reputation; Barnet, M., Pollock, T., Eds.; Oxford University Press: Oxford, UK, 2012; pp. 94-113.

39. Galenson, D.W. The life cycles of modern artists. Theory and implications. Hist. Methods 2004, 37, 123-136.

40. Lang, G.E.; Lang, K. Recognition and renown: The survival of artistic reputation. Am. J. Sociol. 1988, 94, 79-109.

41. Lang, G.E.; Lang, K. Etched in Memory: The Building and Survival of Artistic Reputation; University of North Carolina Press: Chapel Hill, NC, USA, 1990.

42. Rhee, P.; Haunschild, P. The liability of a good reputation: A study of product recalls in The US. Automobile Industry. Organ. Sci. 2006, 17, 101-117.

43. Rindova, V.P.; Williamson, I.O.; Petkova, A.P.; Sever, J.M. Being good or being known: An empirical examination of the dimensions, antecedents, and consequences of organizational reputation. Acad. Manag. J. 2005, 48, 1033-1049.

44. Gardberg, N.; Fombrun C.; The global reputation quotient project: First steps toward a cross-nationally valid measure of corporate reputation. Corp. Rep. Rev. 2002, 4, 303-307.

45. Elsbach, K.D. Intraorganizational institutions. In The Blackwell Companion to Organizations; Baum, J., Ed.; Wiley Blackwell Press: Oxford, UK, 2002; pp. 37-39.

46. Martins, L.L. A model of the effects of reputational rankings on organizational change. Organ. Sci. 2005, 16, 701-720.

47. Rowe, W.G.; Harris, I.C.; Cannella, A.A.; Francolini, T. In search of meaning: Does the fortune reputation survey alter performance expectations? J. Admin. Sci. 2003, 20, 187-195.

48. Thompson, J.D. Organizations in Action; McGraw-Hill: New York, NY, USA, 1967.

49. Bothner, M.; Podolny, J.; Smith, E. Organizing contests for status: The Matthew Effect vs. The Mark Effect. Manag. Sci. 2011, 57, 439-457. 
50. Shrum, W.; Wuthnow, R. Reputational status of organizations in technical systems. Am. J. Sociol. 1988, 94, 882-912.

51. Alpert, H.E. Durham's functional theory of rituals. Sociol. Soci. Res. 1938, 23, 103-108.

52. Durkheim, E. The Elementary Forms of the Religious Life; Free Press: New York, NY, USA, 1965.

53. Roth, A.L. Mean wearing masks: Issues of description in the analysis of ritual. Sociol. Theory 1995, 13, 301-327.

54. Gluckman, M. Custom and Conflict in Africa; Blackwell: Oxford, UK, 1965.

55. Lukes, S. Political ritual and social integration. Sociology 1975, 9, 289-308.

56. Appadurai, A. Introduction: Commodities and the politics of value. In The Social Life of Things; Appadurai, A., Ed.; Cambridge University Press: Cambridge, UK, 1986; pp. 3-63.

57. Smith, A.C.T.; Stewart, B. Organizational rituals: Features, functions and mechanisms. Int. J. Manag. Rev. 2011 13, 113-133.

58. Bell, C. Ritual Theory, Ritual Practice; Oxford University Press: Oxford, UK, 1992.

59. Meyer, J.W.; Rowan, B. Institutional Organizations: Formal structure as myth and ceremony. Am. J. Sociol. 1997, 83, 340-362.

60. Merton, R. The Mathew Effect in science. Science 1968, 159, 56-63.

61. Bothner, M.; Kim, Y.; Smith, E. How does status affect performance? Status as an asset vs. status as a liability in the PGA and NASCAR. Organ. Sci. 2012, 23, 416-433.

62. Cialdini, R.B.; Borden, R.J.; Thorne, A.; Walker, M.R.; Freeman, S.; Sloan, L.R. Basking in reflected glory: Three (football) field studies. J. Pers. Soc. Psychol. 1976, 34, 366-375.

63. March, J.C.; March, J.G. Performance sampling in social matches. Admin. Sci. Q. 1978, 23, 434-453.

64. Oliver, C. Strategic responses to institutional processes. Acad. Manag. Rev. 1991, 16, 145-179.

(C) 2014 by the authors; licensee MDPI, Basel, Switzerland. This article is an open access article distributed under the terms and conditions of the Creative Commons Attribution license (http://creativecommons.org/licenses/by/3.0/). 